has an honorary senior lectureship, and one has a clinical consultant post. In comparison, up to April 2014, 76\% of CLs in all specialties continued in an academic post. PACTs members have also published over 100 research papers since 2009 .

Discussion A national peer support network for IATs in palliative medicine is particularly important because the small number of posts limits local support. PACTs works well, and is considered helpful by members. Career progression for PACTs members compares favourably to national averages for IATs. This peer support model could be used elsewhere to support clinical academic training in palliative medicine.

\section{P-59 FACILITATING COLLABORATIVE WORKING WITH A PATIENT CENTRED STUDY DAY}

${ }^{1}$ Kate Shorthose, ${ }^{1}$ Anitia Brigham, ${ }^{2}$ Dawn Giblett, ${ }^{3}$ Helen Davies. 'St Margerets Hospice, Taunton, Somerset; ${ }^{2}$ Musgrove Park Hospital, Taunton, Somerset; ${ }^{3}$ Yeovil District General Hospital, Yeovil, Somerset

\subsection{6/bmjspcare-2017-00133.59}

Background A new heart failure service had recently been developed with input from the local palliative care team. Feedback from an initial joint study day was positive but felt to be too power point heavy.

A further study day was planned, with a more interactive approach. It was attended by GPs, specialist nurses and staff nurses from hospital and community settings.

Methods A programme was developed with sessions focussed around a patient's journey from diagnosis until last days of life. The sessions were led by heart failure and palliative care professionals and included a patient story. Participants were seated around tables with a facilitator on each, for group discussions about treatment decisions and specific challenges arising from the different stages of the disease.

Evaluation forms included before and after self-assessments of knowledge and confidence by the participants for each session and also asked candidates how it would change their practice.

Results $96 \%$ of participants providing feedback (25 of 26) reported an increase in confidence and better understanding of the topics covered, with improved scores before and after the teaching. The majority gave examples of changes to practice, especially around advanced care planning. Feedback was extremely positive in favour of the holistic, multidisciplinary approach and central role of the patient's story.

Conclusions The model promoted collaborative working between the palliative and heart failure teams with a better understanding of each other's role and appreciation that an integrated approach can potentially improve patient care.

Using the story of an individual patient gave more relevance and a personal aspect to the teaching sessions which was appreciated by the attendees.

There is potential for this model to be used for other noncancer patient groups such as long term neurological conditions and chronic respiratory disease to strengthen local collaborative working between palliative care and these specialities also.

\section{P-60 A PILOT SURVEY OF EDUCATIONAL AND DEVELOPMENT OPPORTUNITIES AND SUPPORT AVAILABLE TO SSAS DOCTORS WORKING IN PALLIATIVE MEDICINE IN EAST AND WEST SUSSEX}

Sara McLintock, Jane Lewington. Martlets Hospice (Sussex Community NHS Foundation Trust), Hove, UK

\subsection{6/bmjspcare-2017-00133.60}

Introduction Specialty Doctors, Staff Grade and Associate Specialist (SSAS) Doctors comprise a higher workforce percentage in palliative medicine (PM) than in other secondary care specialties (19-20\% vs 9\%). ${ }^{1,2,3}$ These grades are usually considered "non-training" but employers are expected to provide educational development support. ${ }^{4}$ The APM annual census examines workforce and workload issues ${ }^{1}$ but this survey aimed to discover what educational support is available. SSAS doctors working in East and West Sussex (EWS) were surveyed about educational development opportunities, support to access these opportunities, appraisal and future career plans.

Methods Eighteen SSAS doctors in PM in EWS were invited to complete a short online survey asking questions about educational and development opportunities.

Results Eleven people (61\%) responded to the survey, although one did not complete several questions. The main results are shown in Table 1 with figures for the rest of England shown where available.

\begin{tabular}{lll} 
Abstract P-60 Table 1 & & \\
\hline & EWS n (\%) & England (\%) \\
\hline Female & $11 / 11(100)$ & 81 \\
Less-than-full-time & $11 / 11(100)$ & 77 \\
Named supervisor & $7 / 10(70)$ & \\
Annual appraisal & $10 / 10(100)$ & 90 \\
Allocated SPA time & $9 / 10(90)$ & \\
Protected SPA time & $2 / 9(22)$ & \\
Study Leave in last 12 months & $11 / 11(100)$ & \\
Study Leave funding granted & $9 / 10(90)$ & \\
Course attendance encouraged & $9 / 10(90)$ & \\
Hospice Journal Club & $5 / 10(50)$ & \\
Access to regular teaching & $3 / 10(30)$ & \\
Would like more educational opportunities & $8 / 10(80)$ & \\
Audit/Quality Improvement project in last 2 years & $9 / 10(90)$ & \\
Plan to sit/sat exams in last 2 years & $2 / 10(20)$ & \\
Regularly teach others & $7 / 9(78)$ & \\
Attended teaching skills course & $4 / 10(40)$ & \\
Poor/no access to online journals & $3 / 10(30)$ & \\
Plan for CESR/Article 14 & $2 / 10(20)$ & \\
\hline
\end{tabular}

Discussion This pilot survey (with 61\% response rate) shows SSAS doctors in EWS are generally well supported with $90 \%$ allocated SPA time and study leave with expenses. They are educationally active doing Audit/Quality Improvement projects and teaching others. At least $2 / 10$ plan to go the CESR/Article 14 route. Areas for improvement include more/better online resource access, and locally provided teaching. Of concern, 
only $2 / 10$ had 'protected' SPA time (an important factor in maintaining adequate Continuing Personal Development). This small pilot study is to be extended across the region.

\section{REFERENCES}

1. http://apmonline.org/wp-content/uploads/2015/04/web-version_2015-Analysis_FINAL_100816.pdf

2. http://apmonline.org/wp-content/uploads/2015/04/APM-Workforce-Report-for-Palliative-Medicine-2012-2016.pdf

3. http://digital.nhs.uk/catalogue/PUB16931/nhs-staf-2014-med-dent-detl-tab.xls

4. http://www.nhsemployers.org/ /media/Employers/Documents/Pay\%20and\% 20reward/Supporting_spec_doctors-guide_good_practice_cd_290408.pdf

\section{P-61 DANGEROUS VARIATIONS IN EQUIANALGESIC DOSING FOR TRANSDERMAL FENTANYL}

Anna Bradley, Andrew Davies. Royal Surrey County Hospital, Guildford, UK

10.1136/bmjspcare-2017-00133.61

Background Opioid rotation/switching is common in palliative care, and one of the most common switches is between oral morphine and transdermal fentanyl. The purpose of this review was to highlight the wide variation in equianalgesic doses that exists according to different sources.

Method In January 2016, we reviewed national guidelines and Summaries of Product Characteristics for transdermal fentanyl preparations available in the United Kingdom, to determine recommended equianalgesic doses for oral morphine and transdermal fentanyl.

Results

\begin{tabular}{llllll}
$\begin{array}{l}\text { Abstract P-61 Table 1 } \\
\text { from different sources }\end{array}$ & Examples of oral morphine dose variations \\
\hline Source & \multicolumn{5}{c}{ Fentanyl dose (micrograms/hour) } \\
\cline { 2 - 7 } & 12 & 25 & 50 & 75 & 100 \\
\hline BNF & 30 & 60 & 120 & 180 & 240 \\
PCF (stable dose for several weeks) & & $<135$ & $135-$ & $225-$ & $315-$ \\
& & & 224 & 314 & 404 \\
PCF (stable dose for long periods) & $<44$ & $45-89$ & $90-149$ & $150-$ & $210-$ \\
& & & & 209 & 269 \\
Durogesic Dtrans (stable dose for several & & $<135$ & $135-$ & $225-$ & $315-$ \\
weeks) & & & 224 & 314 & 404 \\
$\begin{array}{l}\text { Durogesic Dtrans (stable dose for long } \\
\text { periods) }\end{array}$ & $<44$ & $45-89$ & $90-149$ & $150-$ & $210-$ \\
Fencino (opioid rotation due to adverse & $<90$ & $90-$ & $135-$ & $225-$ & $315-$ \\
reaction) & & 134 & 224 & 314 & 404 \\
Fencino (stable, well tolerated opioid & $<60$ & $60-89$ & $90-149$ & $150-$ & $210-$ \\
therapy) & & & & 209 & 269 \\
\hline
\end{tabular}

See Table 1. As can be seen from the Table, there can be up to a threefold difference in dose of oral morphine for a specific dose of transdermal fentanyl ie, 12 micrograms/hour $=30$ $\mathrm{mg}$ or $90 \mathrm{mg}$.

Conclusions This review highlights clinically significant (and potentially dangerous) differences in equianalgesic doses of transdermal fentanyl. We would suggest that there needs to be a national/international consensus on equianalgesic doses for transdermal fentanyl.

\section{P-62 RESPONSE TO ONCOLOGICAL TREATMENTS: WHAT OUTCOMES DO ONCOLOGISTS AND PALLIATIVE MEDICINE PHYSICIANS CHOOSE?}

Anna Bradley, Andrew Davies. Royal Surrey County Hospital, Guildford, UK

\subsection{6/bmjspcare-2017-00133.62}

Background There are a variety of ways of describing response to oncological treatments eg, response rate, progression-free survival and overall survival. However, there is limited information about the terminology preferences of oncologists or palliative medicine physicians.

Method All oncologists and palliative medicine physicians (including consultants, specialty trainees and "other" doctors) from four cancer centres in the United Kingdom were contacted in April 2016 to complete an online survey.

The question that was posed was as follows: "A new treatment is developed for carcinoma of the umbilicus which increases the median survival of patients from six months to twelve months. However, $75 \%$ of patients have an objective decrease in size of the tumour after six months of treatment. How would you explain the new treatment to a patient with carcinoma of the umbilicus?" Potential responses were: "with treatment you have a $50 \%$ chance of surviving twelve months"; "treatment will double your life expectancy"; "the new treatment is a "game changer"'; "treatment will increase your life expectancy by six month"; and "75\% of patients will respond to treatment".

Results There were 111 responses in total (oncologists=97, palliative medicine physicians=14). Table 1 demonstrates the range of responses.

\begin{tabular}{|c|c|c|}
\hline Possible response & Oncology & $\begin{array}{l}\text { Palliative } \\
\text { Medicine }\end{array}$ \\
\hline $\begin{array}{l}\text { With treatment you have a } 50 \% \text { chance of surviving } \\
\text { twelve months }\end{array}$ & $18 \%$ & $14 \%$ \\
\hline Treatment will double your life expectancy & $8 \%$ & $7 \%$ \\
\hline The new treatment is a 'game changer' & $2 \%$ & $7 \%$ \\
\hline Treatment will increase your life expectancy by six months & $38 \%$ & $29 \%$ \\
\hline $75 \%$ of patients will respond to treatment & $34 \%$ & $43 \%$ \\
\hline
\end{tabular}

Conclusions In both groups, the most popular answers were "treatment will increase your life expectancy by six months" and " $75 \%$ of patients will respond to treatment", with more oncologists talking about increase in survival and more palliative medicine physicians talking about response rates. These results were somewhat surprising, and so we plan to explore this issue further with a new mixed method research study.

\section{P-63 SUBCUTANEOUS LEVETIRACETAM FOR THE MANAGEMENT OF SEIZURES AT THE END OF LIFE}

\footnotetext{
${ }^{1}$ Anna Sutherland, ${ }^{2} J o h n$ Curtin, ${ }^{2}$ Victoria Bradley, ${ }^{3}$ Maggie Presswood, ${ }^{4}$ Olivia Bush, ${ }^{3}$ Victoria Hedges, ${ }^{1}$ Katrien Naessens. ${ }^{1}$ Sue Ryder Hospice Nettlebed, Chalgrove, UK; ${ }^{2}$ Florence Nightingale Hospice, Stoke Mandeville Hospital, Mandeville Road, Aylesbury; ${ }^{3}$ Sir Micael Sobell House Hospice, Churchill Hospital, Headington, Oxford; ${ }^{4}$ Katharine House Hospice, Aynho Road, Adderbury
}

10.1136/bmjspcare-2017-00133.63 